\title{
Manual de PROJeto de estações de tRatamento de esgotos VOLUME I - OS SISTEMAS DE TRATAMENTO
}

\begin{abstract}
Patrício Gallegos CREsPo
Este livro do Professor Gallegos C., da UFMG, engenheiro-arquiteto de formação e com especialização em engenharia sanitária, é fruto de sua experiência mais prática e menos acadêmica, como frisa, e que, portanto, a considera como a sua verdade, expondo de maneira franca, a sua forma de pensar e atuar em ensino e na prática. Este Volume 1 consiste de 9 capítulos, sendo que os 2 iniciais se referem, um a critérios de projeto e o outro a conceitos de parâmetros de poluição; nos 4 capítulos seguintes são abordados de

pletas, prejudicando a compreensão; os principais parâmetros de projeto poderiam ser reunidos mais em quadros, semelhantes aos dos lembretes e observaçôes utilizados, já que se enfatiza tanto o lado prático; embora a parte teórica esteja num linguajar bem simples, existem algumas imprecisōes; há necessidade ainda de revisão de alguns cálculos nos exemplos, de algumas unidades com simbologia errada (e até dois símbolos para a mesma unidade), e alguns dos valores adotados para certos parâmetros
\end{abstract} maneira clássica e acadêmica, o tipo ou nível de tratamento, respectivamente, preliminar, primário, secundário e terciário, este de maneira muito sucinta sobre remoção de nitrogênio e fósforo. $\mathrm{O}$ capítulo seguinte é constituído de uma compilação de vários aspectos de uma norma da ABNT (NBR 12209), sobre os quais o autor tece alguns comentários subjetivos; e finalmente, os dois últimos capítulos, que são mais específicos e voltados para o objetivo principal deste volume, ou seja, os sistemas de tratamento em que o autor aparentemente acumulou a sua experiência maior: lodos ativados, principalmente e, em menor escala, sistemas para pequenas comunidades (decanto-digestores, lagoas, filtros anaeróbios, infiltração no solo e leitos de secagem de lodo).

Inicialmente, no tocante à formatação do livro, percebe-se que dentro de cada capítulo há uma subitemização excessiva e seqüência dos tópicos muitas vezes difíceis de serem seguidas, e, portanto, com prejuízo à visualização e entendimento dos assuntos abordados, não condizentes com o propósito de um manual de projeto. Alguns outros pontos devem ser melhorados e merecem uma revisão cuidadosa: a numeração de várias figuras não confere com a do texto; há uma quantidade demasiada de frases quebradas ou incom-

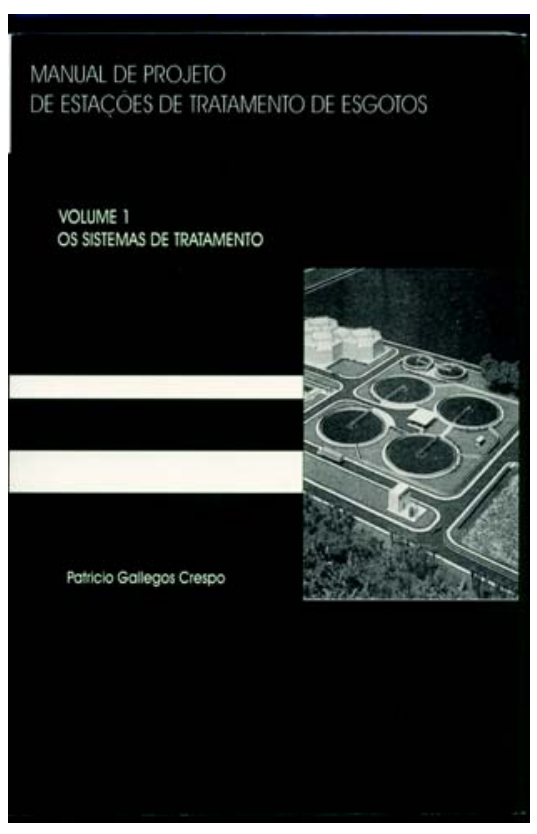

mereceriam uma maior explicação. Este manual de projeto será comercializado através de uma instituição como a ABES, portanto, provavelmente poderá ser muito consultado, independente das controvérsias que poderão ser geradas, por um público que tem à disposição poucas publicações desta natureza no mercado editorial. Seria recomendável, pois, que houvesse a sua catalogação segundo as normas bibliográficas e que as (poucas) referências citadas no tex- to também as seguissem, uma vez que estão de maneira incompleta (algumas adicionalmente estão desatualizadas existindo edições mais recentes, ou então são referências muito antigas) e não há uma lista apropriada para consulta dos possíveis interessados. Existe uma pequena lista de livros colocada em local inadequado e parece ser mais um comercial de venda de livros, apesar de se citar nomes de colega e instituições conceituados.

No tocante ao conteúdo, chama a atenção (i) os conceitos e terminologia empregados pelo autor e a excessiva ênfase da experiência que atribui a si próprio, por um lado, e um desconhecimento daquela pela comunidade acadêmica, por outro lado; e (ii) a necessidade de uma melhor precisão e até correção para alguns conceitos teóricos ou termos práticos muito importantes, como idade do lodo e tempo de detenção hidráulico; carga hidráulica e velocidade; carga e concentração de matéria orgânica; sólidos suspensos voláteis, biomassa, lodo, microrganismos e vida biológica (termo do autor); eutrofização, metabolismo e outros. A falta dessa conceituação mais precisa, pode passar uma idéia inadequada e sem rigor da terminologia usualmente empregada na área de tratamento de esgotos. $\mathrm{O}$ vernáculo empregado no livro apresenta-se com imperfeiçōes e falta de uniformidade, merecendo também uma revisão específica. Para iniciantes no tema, possivelmente haverá uma dificuldade adicional para a compreensão da operação dos sistemas de tratamento, pela falta de maiores explicaçóes, ainda que sucinta, sobre o funcionamento de cada unidade, em termos de fenômenos físicos, químicos e biológicos que são a essência do tratamento.

Numa avaliação geral, o livro pode ter até alguns méritos, por apresentar

\section{Goordemador da columa Livgosa Prof. Gigero Onofae de Amdrade Neto}

A sessão "Livros Técnicos", que a cada edição traz resumos comentados sobre livros de interesse na área, tem como principal objetivo permitir que o leitor, de forma rápida, se atualize e conheça o que há disponível no mercado editorial. As contribuiçōes deverão ser encaminhadas para: esa@abes-dn.org.br 
dados práticos, comentários e observações sobre projeto de estações de tratamento convencionais, embora os tópicos sejam abordados de maneira genérica, sem profundidade, talvez intencionalmente pelo autor, já que dá a entender a existência de conflito entre o saber teórico e prático. Não aborda outros sistemas de tratamento mais recentes e com dados mais atualizados e fruto de experiência de outros colegas, também com grande vivência prática e acadêmica simultânea. Assim, se a intenção para o livro era voltada para projetistas experientes ou com conhecimento de conceitos teóricos, a formatação, a linguagem e o conteúdo deixam a desejar; se para iniciantes, faltam conceitos prévios para a compreensão do funcionamento dos sistemas, correção de termos, de conceitos e de alguns exemplos de cálculo. O livro parece mais, em resumo, o resultado de notas de aula de algum curso do autor, que não teve os devidos cui- dados de revisá-lo para divulgação e comercialização em entidade de âmbito nacional e internacional, portanto, de grande responsabilidade nesta tarefa relevante.

De qualquer maneira, certamente o autor poderá considerar e terá oportunidade de corrigir as imperfeições e até ampliar o conteúdo deste volume, com dados práticos de sistemas eficientes, como por exemplo, o reator anaeróbio tipo UASB e outros sistemas integrados; estes não foram abordados, mesmo no capítulo dedicado a pequenas comunidades, mas não podem faltar em novos manuais, pela sua adequação amplamente comprovada, custos, versatilidade e outras vantagens que oferecem, inclusive para grandes comunidades. Espera-se que o volume II anunciado venha, sem as imprecisões deste volume I e com uma revisão condizente, brindar um público desejoso de atualizações práticas e teóricas, sem discriminação, fruto da experiência de colegas profissionais, doutores ou acadêmicos, os com-títulos ou os sem-títulos, mas todos preocupados em desenvolvimento de tecnologia de tratamento de esgotos apropriada para a nossa realidade.

Comentários feitos por Mario Takayuki Kato Professor Adjunto do Departamento de Engenharia Civil, Escola de Engenharia de Pernambuco, Centro de Tecnologia e Geociências, Universidade Federal de Pernambuco.

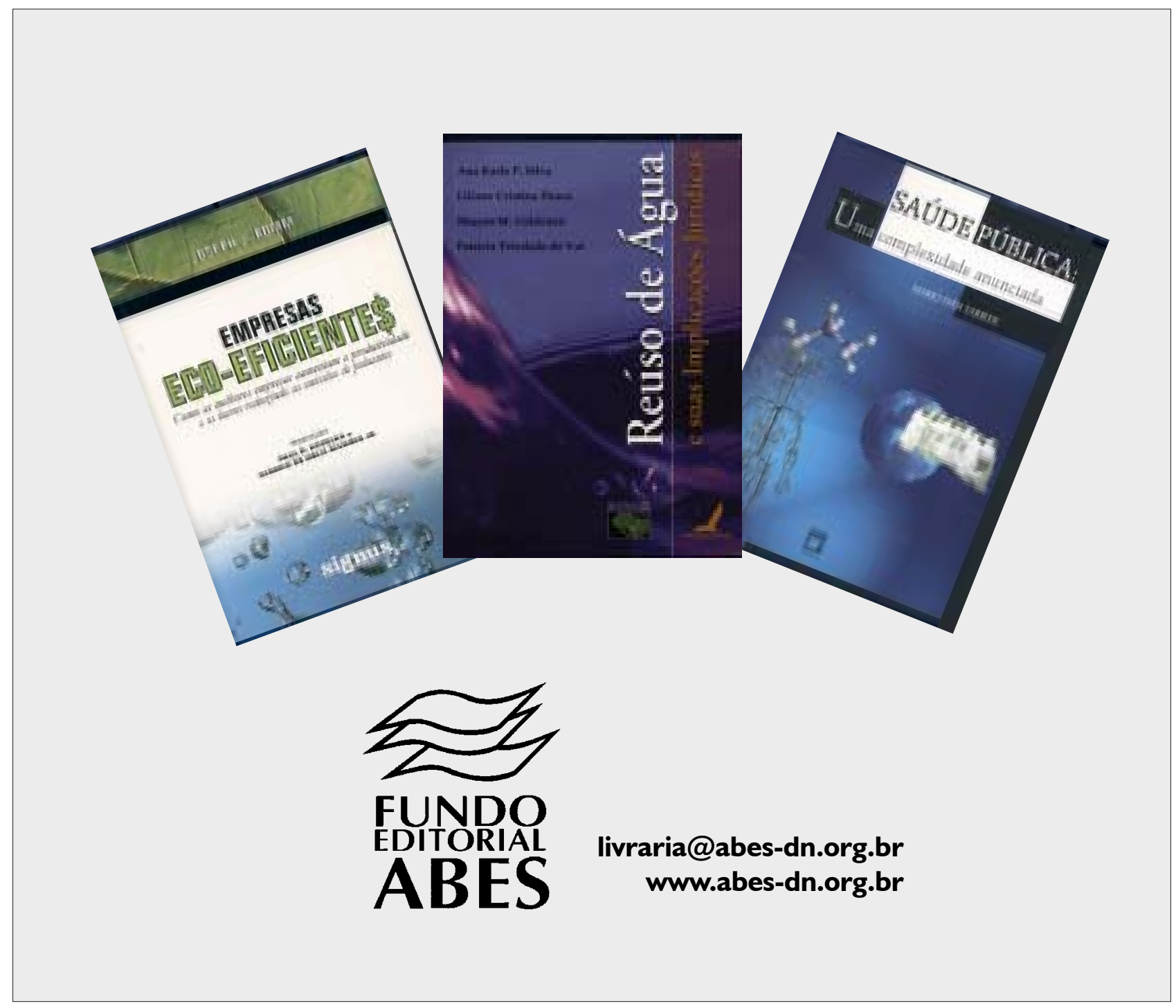

